Acta Crystallographica Section F

Structural Biology

and Crystallization

Communications

ISSN 1744-3091

\section{addenda and errata}

\title{
Crystallization and preliminary X-ray study of the deaminase AmnE from Pseudomonas sp. AP-3. Corrigendum
}

\author{
Dan $\mathrm{Yu}^{\mathrm{a}, \mathrm{b}}$ Yongji Jiang, ${ }^{\mathrm{a}, \mathrm{b}}$ Jianfeng Hou, ${ }^{\mathrm{c}}$ Shuai Chen, \\ Guofang Zhang, ${ }^{a, b}$ Xiang Liu, ${ }^{b}$ Hui Dong ${ }^{b} *$ and ${\mathrm{Bo} \mathrm{Yu}^{\mathrm{c} *}}^{\mathrm{c}}$

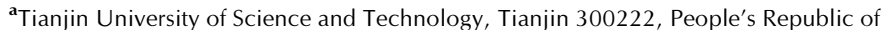 \\ China, ${ }^{\mathbf{b}}$ Tianjin International Joint Academy of Biotechnology and Medicine, Tianjin \\ 300457, People's Republic of China, and 'Institute of Microbiology, Chinese \\ Academy of Sciences, Beijing 100101, People's Republic of China \\ Correspondence e-mail: hui.dong@htmdc.org, yub@im.ac.cn
}

The article by Yu et al. (2013, Acta Cryst. F69, 812-814) is corrected.

In the article by Yu et al. (2013) the Matthews coefficient and solvent content are incorrect. The correct Matthews coefficient should be $2.10 \AA^{3} \mathrm{Da}^{-1}$ instead of $3.15 \AA^{3} \mathrm{Da}^{-1}$, corresponding to a solvent content of $41.53 \%$ instead of $61.02 \%$. In Table 1 the resolution range should be 50.00-2.09 $\AA$. The number of observed reflections should be 319580 (10109) instead of 22932 (752), and the number of unique reflections should be 23327 (1087) instead of 14970 (708).

\section{References}

Yu, D., Jiang, Y., Hou, J., Chen, S., Zhang, G., Liu, X., Dong, H. \& Yu, B. (2013). Acta Cryst. F69, 812-814. 